\title{
REUSE THE BED ASH FROM CIRCULATING FLUIDIZED BED COMBUSTION ON MORTAR MIXTURE
}

\author{
Hui-Mi Hsu \\ Department of Civil Engineering, National Ilan University, Ilan, Taiwan, R.O.C.
}

An Cheng

Department of Civil Engineering, National Ilan University, Ilan, Taiwan, R.O.C., ancheng@niu.edu.tw

Sao-Jeng Chao

Department of Civil Engineering, National Ilan University, Ilan, Taiwan, R.O.C.

Follow this and additional works at: https://jmstt.ntou.edu.tw/journal

Part of the Civil and Environmental Engineering Commons

\section{Recommended Citation}

Hsu, Hui-Mi; Cheng, An; and Chao, Sao-Jeng (2010) "REUSE THE BED ASH FROM CIRCULATING FLUIDIZED BED COMBUSTION ON MORTAR MIXTURE," Journal of Marine Science and Technology. Vol. 18: Iss. 4, Article 19. DOI: $10.51400 / 2709-6998.1930$

Available at: https://jmstt.ntou.edu.tw/journal/vol18/iss4/19

This Research Article is brought to you for free and open access by Journal of Marine Science and Technology. It has been accepted for inclusion in Journal of Marine Science and Technology by an authorized editor of Journal of Marine Science and Technology. 


\section{REUSE THE BED ASH FROM CIRCULATING FLUIDIZED BED COMBUSTION ON}

MORTAR MIXTURE

\section{Acknowledgements}

The authors are grateful for the support of this research by National Science Council, ROC, under contract No. NSC 96-2218-E-197-003. 


\title{
REUSE THE BED ASH FROM CIRCULATING FLUIDIZED BED COMBUSTION ON MORTAR MIXTURE
}

\author{
Hui-Mi Hsu*, An Cheng*, and Sao-Jeng Chao*
}

Key words: mortar, durability, absorption, chloride, circulating fluidized bed combustion.

\begin{abstract}
This paper investigates mortars consisting of various circulating fluidized bed combustion (CFBC) bed ash contents. The CFBC bed ash used in this study was obtained from Taiwan's petroleum industry. This study presents experimental results on the flowability, compressive strength, drying shrinkage, scanning electronic microscopy (SEM) and mercury intrusion porosimetry (MIP) of mortar samples containing CFBC bed ash. The initial surface absorption tests (ISAT) and rapid chloride penetration test (RCPT) of mortar were used to measure water absorption and the ability to resist chloride ion characteristics for different mortar samples containing CFBC bed ash. CFBC bed ash is X-ray amorphous and consists of $\mathrm{SiO}_{2}, \mathrm{Al}_{2} \mathrm{O}_{3}$ and $\mathrm{CaO}$ compounds. As more cement is replaced by $\mathrm{CFBC}$ bed ash, the ISA rate increases but the compressive strength decreases. On the other hand, replacing sand with CFBC bed ash increase the compressive strength increases, but the ISA rate decreases. As the CFBC ash content increases, the slump decreases due to a reduction in the fineness modulus and the negative effect of CFBC particles. This study also shows that utilizing the proper amount of CFBC bed ash in mortar significantly improves sulfate resistance.
\end{abstract}

\section{INTRODUCTION}

Circulating fluidized bed combustion (CFBC) is an innovative technology for coal burning that can achieve in situ $\mathrm{SO}_{2}$ removal by injecting calcium-based absorbent into the combustor [1]. The Taiwanese petroleum industry produces approximately 800,000 tons of CFBC ashes annually. Some studies have shown that CFBC ashes have less environmental impact than petroleum coke (p.c.) ashes, which means that CFBC ashes are more marketable by-products [9]. CFBC

Paper submitted 12/17/09; revised 03/07/10; accepted 03/11/10. Author for correspondence: An Cheng (e-mail: ancheng@niu.edu.tw).

*Department of Civil Engineering, National Ilan University, Ilan, Taiwan, R.O.C. flying ash can be used as a soil stabilizer, road base, structural filler, or synthetic aggregate. Sheng's [14] investigation of the self-cementitious properties of fly ash produced by CFBC boilers co-firing coal and high-sulphur petroleum coke showed that high $f$-CaO and $\mathrm{SO}_{3}$ contents are beneficial to self-cementitious, i.e., CFBC fly ash is self-cementitious [7]. Freidin [11] indicated that a high total content of $f$-CaO plus $\mathrm{Ca}(\mathrm{OH})_{2}$ and high $\mathrm{CO}_{3}$ content fly ash is able to develop the compressive strength gradually, and curing significantly affects its strength. Zhang [15] manufactured cement with CFBC fly ash, and found that it increased compressive strength about $30 \%$ of compressive strength at the age of 28 days. However, very few studies mix CFBC bed ash with cement as an admixture. Therefore, this study conducts a series of laboratory tests to assess the properties of concrete mixtures containing various amounts of CFBC bed ash. This study also discusses the effect of bed ash on the workability, drying shrinkage, compressive strength, microstructure, and electrical indication of concrete's ability to resist chloride ion penetration and sulfate resistance. To study the permeation properties of mortar mixed with CFBF bed ash, this study uses the initial surface absorption test (ISAT) to measure the absorption of water by capillary suction.

\section{EXPERIMENTAL DETAILS}

\section{Material Properties}

Type I Portland cement conforming to ASTM C150-07 [3] was used for all mixtures. CFBC bed ash with a specific gravity of 2.83 was also used. Table 1 demonstrates the chemical composition of cement and CFBC bed ash as determined by $\mathrm{x}$-ray fluorescence. $\mathrm{CFBC}$ bed ash is a fine, highly alkaline powder with a fineness of $232 \mathrm{~m}^{2} / \mathrm{kg}$. The total amount of lime $(\mathrm{CaO})$ in CFBC bed ash is almost equal to $50 \%$. The fineness modulus of the fine aggregate was 2.69. Table 2 lists the three mortar mixes with the same water/cementitious ratio of 0.55 used in these experiments. Five different mixtures were prepared using $0 \%$ (control), 5\%, 10\%, 15\%, and $20 \%$ CFBC ash replacement by total amount of the cement, respectively, as A00, A05, A10, A15 and A20. The quantities of Portland cement and CFBC bed ash were varied while the amount of sand remained fixed. Four different mixtures were 
Table 1. Chemical composition (\%) and specific gravity of Portland cement and CFBC bed ash.

\begin{tabular}{lcc}
\hline & cement & CFBC bed ash \\
\hline Specific gravity $\left(\mathrm{g} / \mathrm{cm}^{3}\right)$ & 3.15 & 2.83 \\
$\mathrm{SiO}_{2}$ & 20.6 & 5.24 \\
$\mathrm{Al}_{2} \mathrm{O}_{3}$ & 4.0 & 1.31 \\
$\mathrm{Fe}_{2} \mathrm{O}_{3}$ & 6.1 & 1.14 \\
$\mathrm{CaO}$ & 62.8 & 49.76 \\
$\mathrm{MgO}$ & 2.6 & 1.81 \\
$\mathrm{SO}_{3}$ & 3.1 & 38.95 \\
$\mathrm{Na}_{2} \mathrm{O}$ & - & 0.25 \\
$\mathrm{~K}_{2} \mathrm{O}$ & - & 0.08 \\
$\mathrm{LOI}$ & 1.8 & 0.75 \\
\hline
\end{tabular}

*Loss of ignition

Table 2. Mix design for mortar $\left(\mathrm{kg} / \mathrm{m}^{3}\right)$.

\begin{tabular}{ccccc}
\hline mix no. & water & cement & fine aggregate & CFBC bed ash \\
\hline A00 & 300 & 545 & 1500 & 0 \\
A05 & 300 & 518 & 1500 & 27 \\
A10 & 300 & 491 & 1500 & 55 \\
A15 & 300 & 464 & 1500 & 82 \\
A20 & 300 & 436 & 1500 & 109 \\
B05 & 300 & 545 & 1425 & 75 \\
B10 & 300 & 545 & 1350 & 150 \\
B15 & 300 & 545 & 1275 & 225 \\
B20 & 300 & 545 & 1200 & 300 \\
\hline
\end{tabular}

prepared using 5\%,10\%, 15\%, and 20\% CFBC bed ash replacement by total amount of sand. These mixtures are respectively designated as B05, B10, B15, and B20.

\section{Workability}

The workability of mortar was evaluated by a slump test, following ASTM C1437-07 [6]. The mortar sample was cast in the form of a frustum cone, $100 \mathrm{~mm}$ in diameter at the base, $70 \mathrm{~mm}$ in diameter at the top, and $50 \mathrm{~mm}$ tall. The cone was cast on a drop table, and dropped 25 times in 10 s from a height of $10 \mathrm{~mm}$ by revolving a cam shaft. The resulting diameter of the mortar is defined as the flow.

\section{Drying Shrinkage}

For the shrinkage measurement, prismatic specimens measuring $25.3 \times 25.3 \times 284.6 \mathrm{~mm}$ were prepared. After demolding, the specimens were cured in water for 3 days, and then placed in a humidity cabinet at $23^{\circ} \mathrm{C}$ and $70 \% \mathrm{RH}$ until the age of 28 days. The initial length of all mortar specimens was measured before they were placed in the humidity cabinet. Sample length was also measured at 7 and 28 days of storage.

\section{Compressive Test}

To evaluate the strength development of concrete containing various $\mathrm{CFBC}$ ash contents, this study also conducted

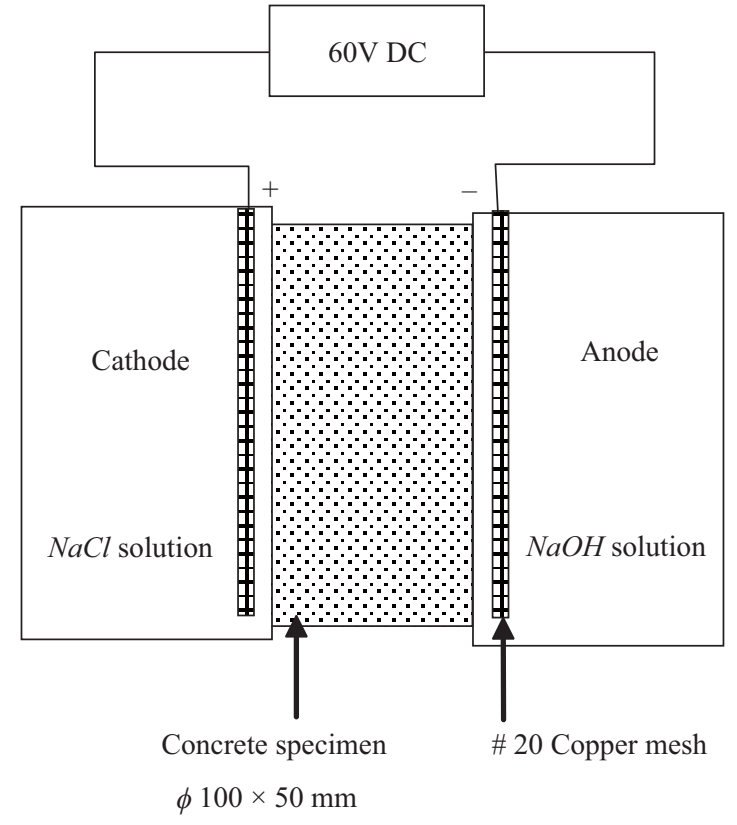

Fig. 1. Schematic diagram of the rapid chloride penetration test.

compressive strength tests in accordance with ASTM C 109-07 [2] at 7, 28, and 56 days. In this study, river sand was partially replaced by particles of bed ash. The shape, texture, and distribution of particle size are the most important factors affecting the strength of mortar. Twenty $\phi 100 \times 200 \mathrm{~mm}$ cylindrical specimens were cast for each batch following the specifications of ASTM C 109. After 24-hour curing, the specimens were demolded and placed in a water tank at room temperature until tested.

\section{Chloride Ion Penetration Test}

This study tested the chloride ion penetration of concrete following ASTM C1202-07 [5]. For each mixture, six cylindrical specimens $(\phi 100 \times 200 \mathrm{~mm})$ were cast and moist-cured for 91 days. Three $50 \mathrm{~mm}$-thick samples were then cut from each cylinder. The sample ring surface was epoxy-coated and then placed in a desiccator at a vacuum pressure of less than 1 torr. After turning the pump off, the samples were soaked in de-aerated water for 18 hours. Sodium hydroxide solution $(0.3 \mathrm{~N} \mathrm{NaOH})$ and sodium chloride solutions $(3 \% \mathrm{NaCl}$ by mass) were then poured into the chamber on both sides of concrete sample, with $\mathrm{NaOH}$ as the anodic electrolyte and $\mathrm{NaCl}$ as the cathodic electrolyte. Figure 1 illustrates the set up of this rapid chloride penetration test (PCPT). During the test, a voltage of $60 \mathrm{~V}$ was continuously applied to the specimens and the current was recorded at 15 minute intervals for a six-hour period. The total charge-passed was obtained by integrating the current vs. time curve.

\section{Initial Surface Absorption Test}

The initial surface absorption test was carried out according to BS 1881 [8]. Figure 2 illustrates the ISAT set-up. 


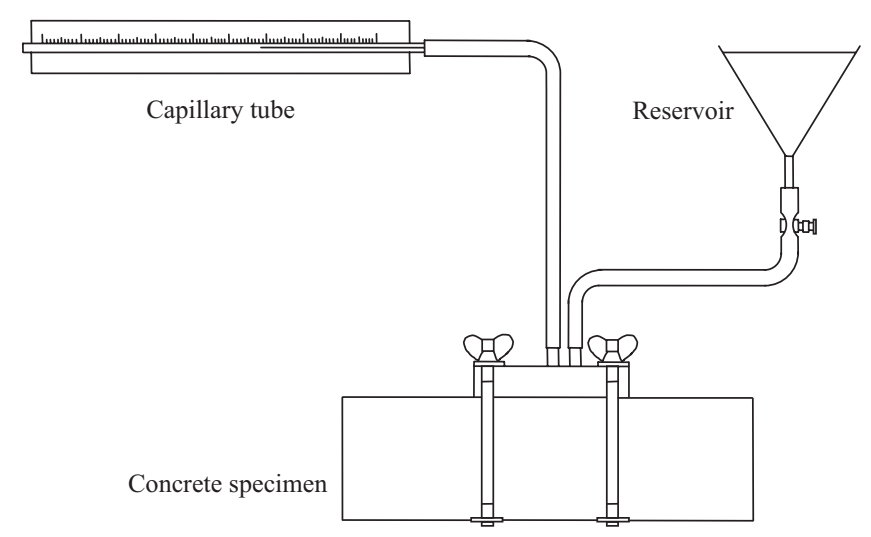

Fig. 2. Schematic ISAT arrangement.

Test specimen was a cylinder measuring $100 \mathrm{~mm}$ in diameter and $50 \mathrm{~mm}$ long. For the tests, the rate of water absorption on the surface zone of the mortar samples is determined during a prescribed period under a head of $200 \mathrm{~mm}$ of water. The rate of initial surface absorption is expressed in $\mathrm{ml} / \mathrm{ml}^{2}$-s.

\section{Sulfate Resistance}

To evaluate the resistance of ash concretes of CFBC subjected to sulfate attack, this study performed sulfate-immersion tests following ASTM C267-01 [4]. Sulfate ions might be the result of seawater or contaminated ground water. The volume expansion caused by this chemical reaction induces internal stresses, which may cause internal cracks and eventually lead to failure. The specimens were $50 \times 50 \times 50 \mathrm{~mm}$ cubes that cured in water until testing. After weight measurements, the specimens were immersed in a saturated sulfate solution for 24 hours and then oven-dried at a constant temperature of $110 \pm$ $5^{\circ} \mathrm{C}$ for another 24 hours. The previous wet-and-dry procedure was repeated seven times and the weight losses and strength reduction of the specimens were recorded after every cycle. The appearance of the immersed-specimens was also observed.

\section{SEM Observation}

A Hitachi model S-510 scanning electron microscope (SEM) was used for microstructure observation. Specimens measuring $5 \mathrm{~mm}(l) \times 5 \mathrm{~mm}(w) \times 3 \mathrm{~mm}(t)$ were prepared by cutting a plate. The specimens were located $5 \mathrm{~cm}$ from the surface of the cylindrical and oven-dried for 24 hours, vacuumed the pressure up to 0.1 torr, and Au-ion spotted for 2 3 min.

\section{Mercury Porosity}

The distribution of the pore size and the pore volume were measured using a Micromeritics Autopore 9500 porosimeter. Two cubic centimeter samples were oven dried for $24 \mathrm{~h}$ at $105^{\circ} \mathrm{C}$ before analysis. Two MIP measurements were taken for each sample. By modeling the pores as cylindrical channels, the test pressure $(p)$ can be connected to the radius of these cylinders by the Washburn-Laplace law:

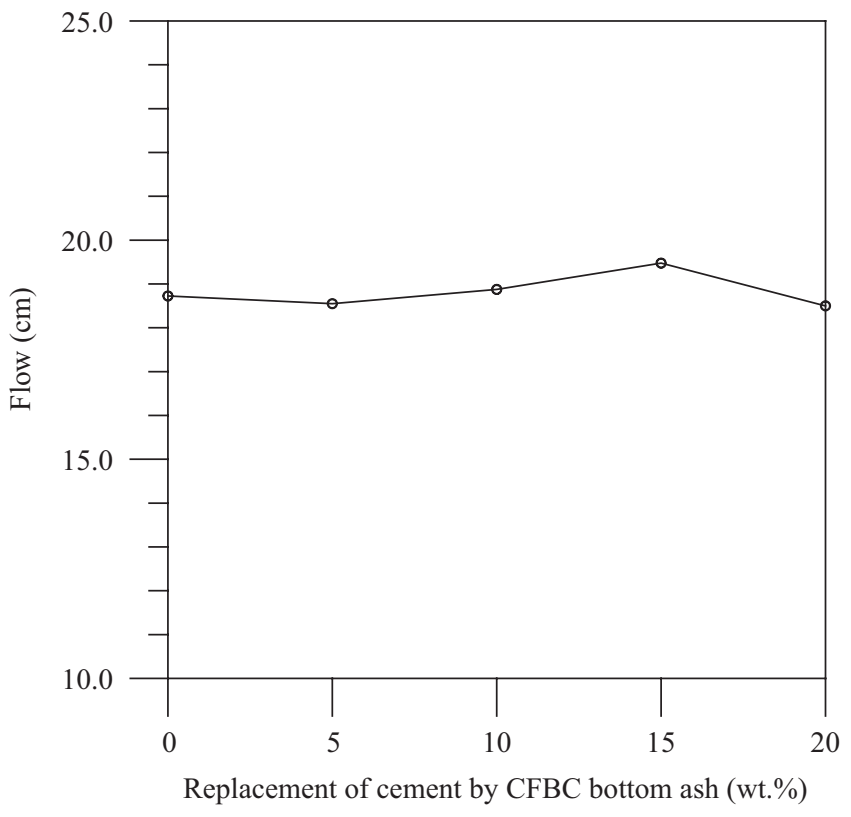

Fig. 3. Effect of CFBC bed ash on the flow (Mix A).

$$
p=\frac{2 \sigma \cos \theta}{r}
$$

where $p$ defines the mercury intrusion pressure $(\mathrm{Pa}), \sigma$ represents the surface tension of mercury $(\mathrm{N} / \mathrm{m}), \theta$ is the contact angle between mercury and pore walls (rad), and $d$ is the equivalent diameter of the intrude pore $(\mathrm{m})$.

\section{RESULTS AND DISCUSSION}

\section{Workability}

The slumps for the control mixtures were $189 \mathrm{~mm}$. As the CFBC ash content increases, the slump decreases. This is due to a reduction in the fineness modulus and the negative effect of CFBC particles as Figs. 3 and 4 illustrate. Figure 4 shows that the addition of CFBC lowers the workability, as the flow decreases from 187 to $149 \mathrm{~mm}$. This is due to the increased cohesiveness of the mixtures caused by the fine particle sizes of the CFBC bed ash.

\section{Drying Shrinkage}

Figures 5 and 6 present the results of drying shrinkage or length change of the mortar sample. These figures show that mortar containing CFBC bed ash shrank less than PC mortar after 7 days. However, this may be due to free lime and $\mathrm{MgO}$ content of $\mathrm{CFBC}$ bed ash. Note that the $\mathrm{SO}_{3}$ content of CFBC bed ash is very high. This might be another reason why the CFBC bed ash from mortar shrank less than the PC mortar after 7 days.

\section{CFBC Bed Ash Effect on Compressive Strength}

Figures 7 and 8 show the compressive strength data ob- 


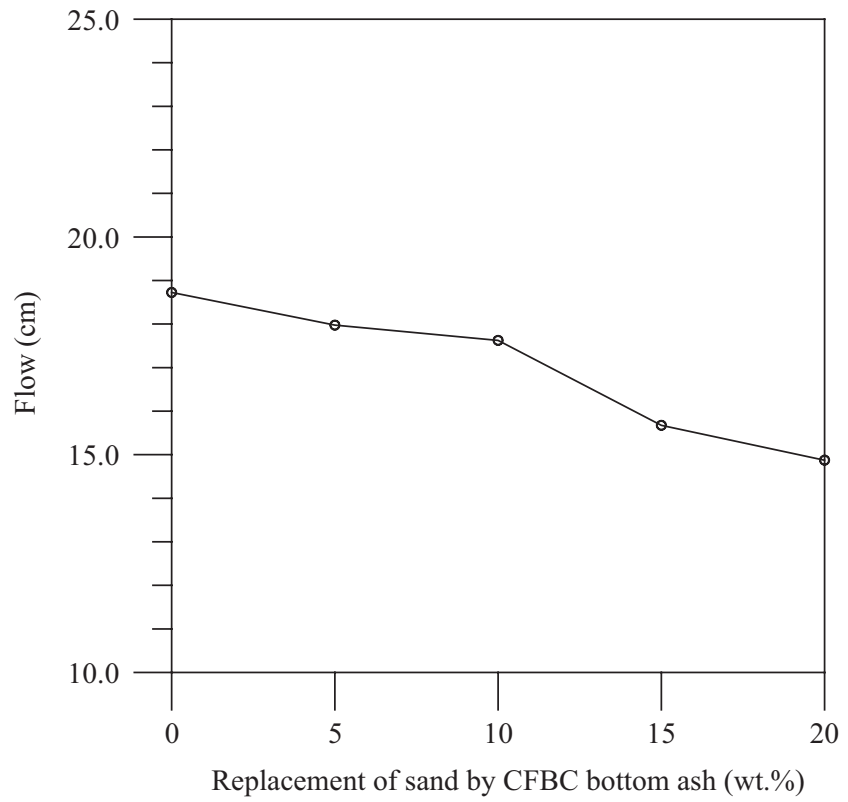

Fig. 4. Effect of CFBC bed ash on the flow (Mix B).

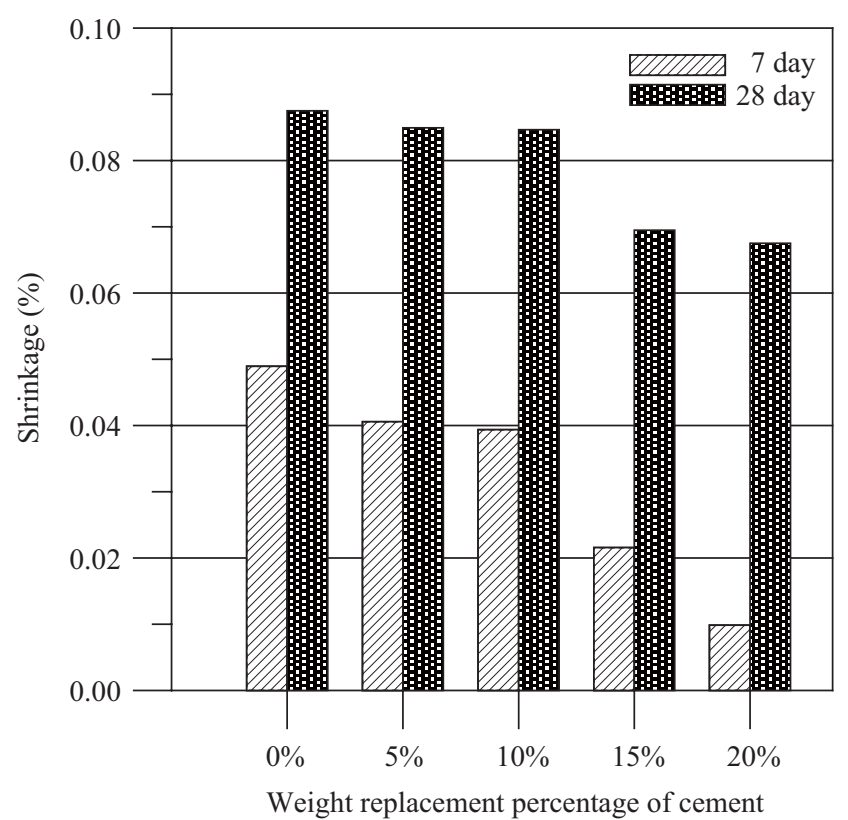

Fig. 5. Shrinkage of mortar produced versus time (Mix A).

tained for mixtures at a water/binder ratio of 0.55 (by weight). The major observation of Fig. 7 is that compressive strength generally decreases as CFBC replaces cement. For all blends, the control mixture (no CFBC) generally produced the highest compressive strength. CFBC alone is not highly cementitious, as Portland cement has more than $60 \%$ free lime, while CFBC bed ash has less than $10 \%$. Therefore, replacing cement with CFBC reduces the cement content and, therefore, decreases strength. However, a small amount of replacement, up to 5\%, does not have a significant adverse effect on strength. At $5 \%$

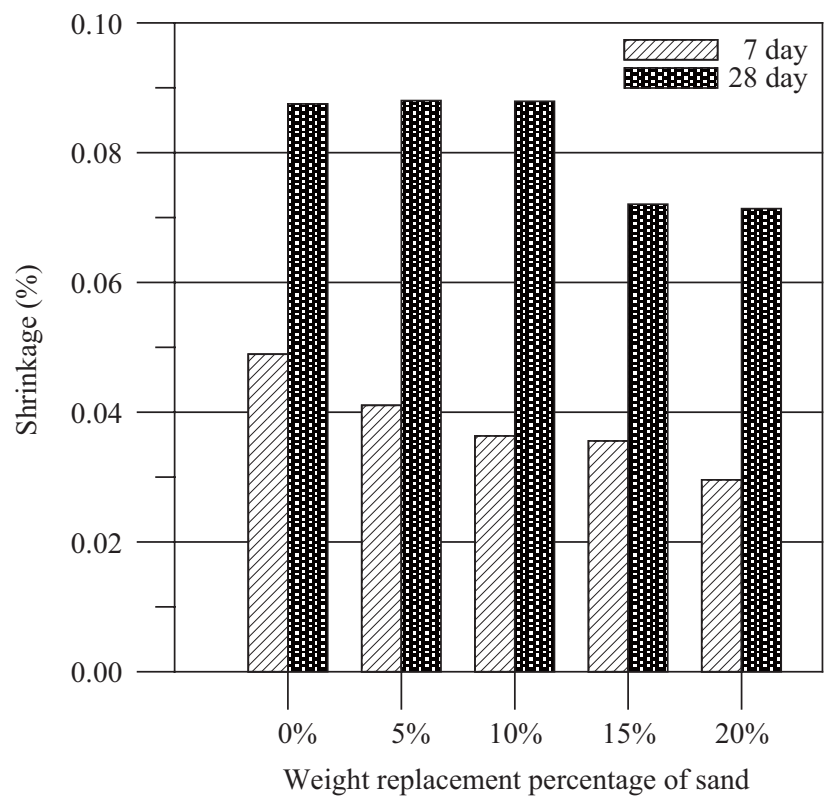

Fig. 6. Shrinkage of mortar produced versus time (Mix B).

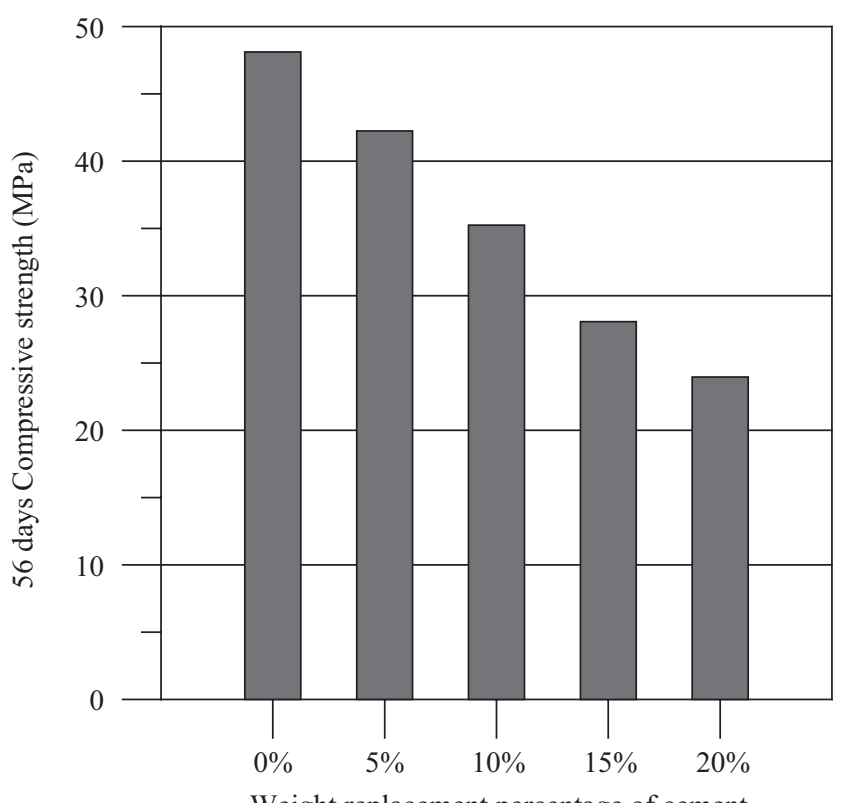

Fig. 7. Effect of CFBC bed ash on the compressive strength (Mix A).

and $20 \%$ CFBC substitution, the reductions in the 56-day compressive strength values were $49.8 \%$ to $87.7 \%$, respectively.

Figure 8 shows the compressive strength of mortars after 56 days for mixture B. This figure indicates that for the same cement contents, mixtures containing CFBC bed ash have higher strength value, which increases as CFBC bed ash is more added to the mixture. However, comparing between the different B mixtures, no strength gain appears by $15 \%$ CFBC bed ash is added to the mix. The amount of CFBC bed ash 


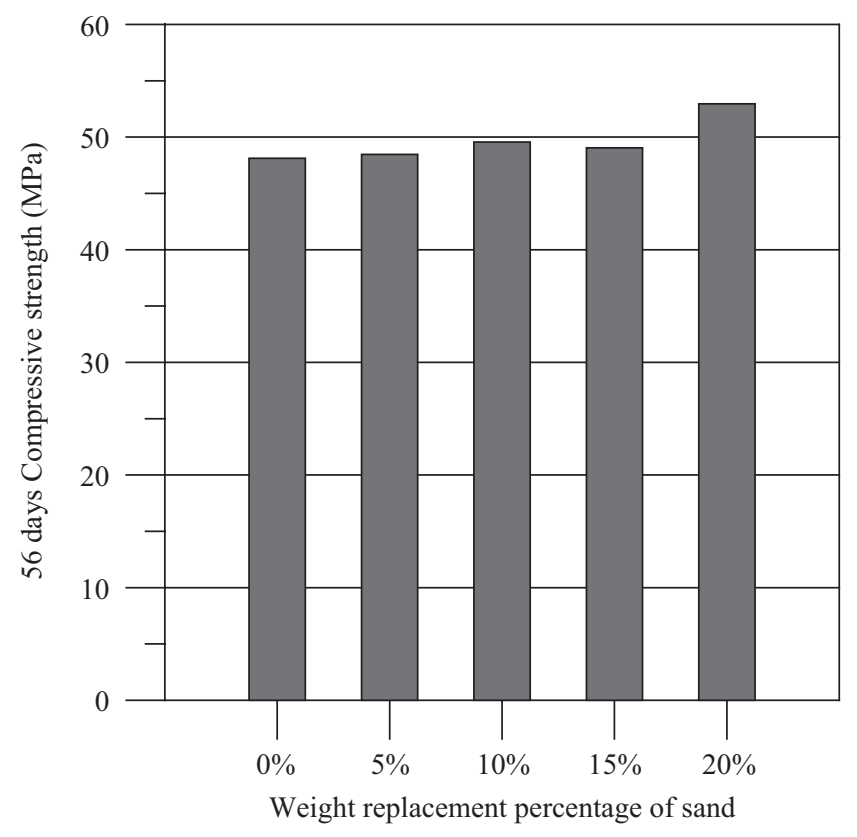

Fig. 8. Effect of CFBC bed ash on compressive strength (Mix B).

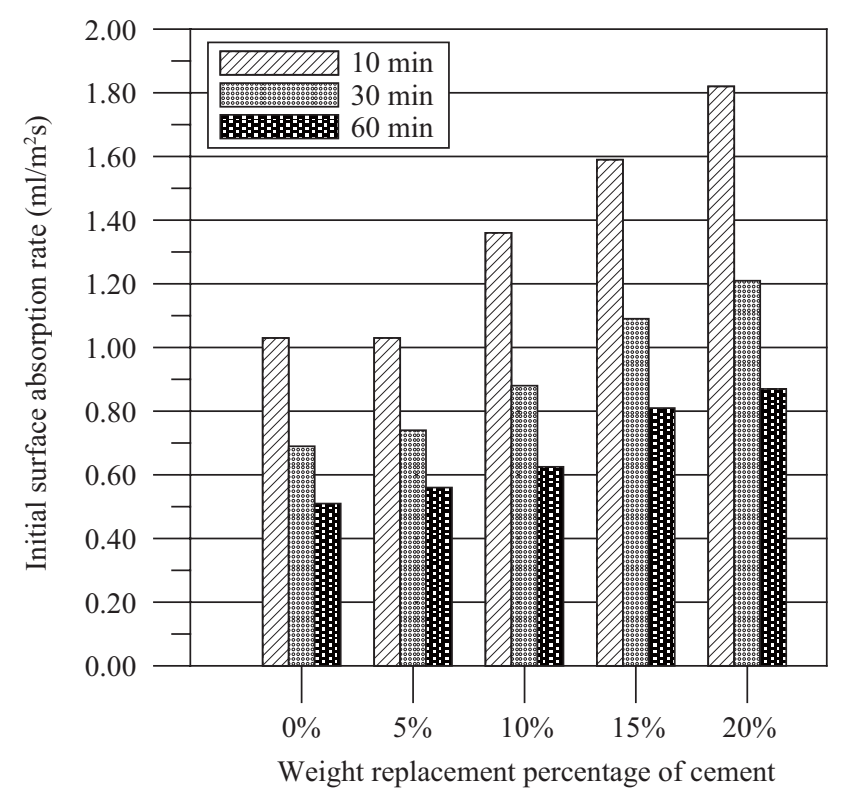

Fig. 9. ISAT plot for Mix A.

replacement for sand, up to $20 \%$, does not seem to have a significant adverse effect on strength.

\section{Effect of CFBC Ash on Hydrated Cement Structure, Permeability, and Chloride Ion Penetration}

The durability of structural concrete is mainly determined by its permeation quality. Most often, researchers use laboratory tests, such as the ISAT and RCPT test, to assess the durability of concrete. Figures 9 and 10 show the ISAT test results at intervals of 10,30 and $60 \mathrm{~min}$. This method provides

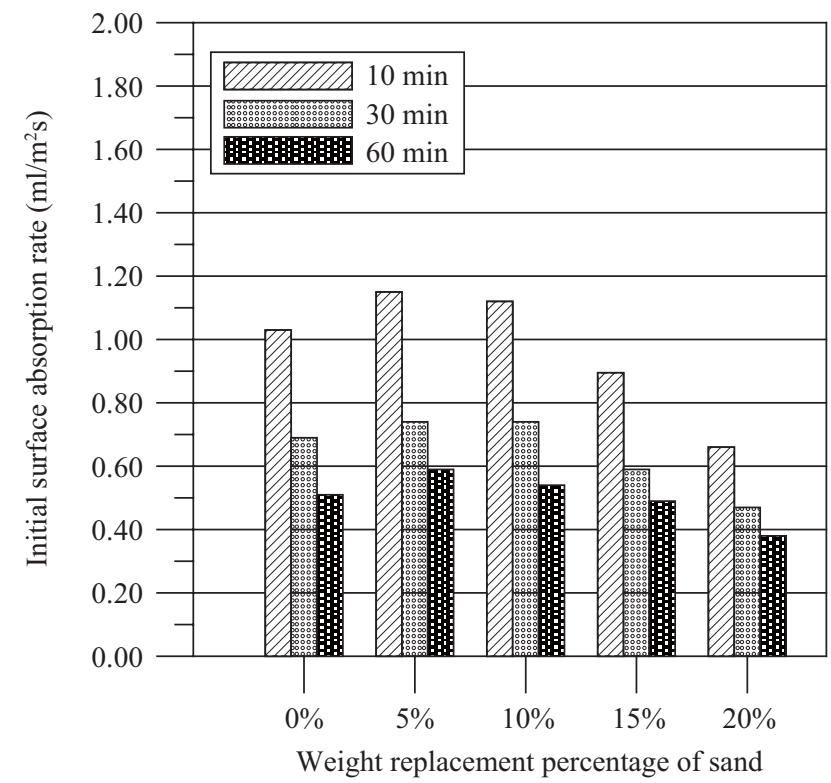

Fig. 10. ISAT plot for Mix B.

three indices of permeation for classifying durability in term of low, medium, or high permeation/absorption. According to Kumar [12], the durability of concrete can be classified in terms of low, average, or high permeability/absorption based on the value of measuring index of permeation. First, an ISA rate higher than $0.2 \mathrm{ml} / \mathrm{m}^{2} \mathrm{~s}$ at 60 minute indicates that the permeation of concrete is high. Second, an ISA ate between 0.1 to $0.2 \mathrm{ml} / \mathrm{m}^{2} \mathrm{~s}$ at 60 minutes indicates that the permeation of concrete is medium. Last, for an ISA lower than $0.1 \mathrm{ml} / \mathrm{m}^{2} \mathrm{~s}$ at 60 minute, the permeation of concrete is low. Absorption increased slightly in B mixes, as the CFBC content increased from 0 to $5 \%$. However, when the CFBC content increased from 10 to $20 \%$, the absorption decreased as more CFBC was added to the mixture. This decrease in absorption may be attributed to a dense pore structure within the mix due to ettringite (AFt) crystal formation.

The SEM images in Fig. 11(a) show no needle-shape ettringite and capillary pores $(0.01$ to $10 \mu \mathrm{m})$ in the ordinary Portland cement specimen. However, Fig. 11(b) shows that a great number of needle-shape ettringite, plate-shape calcium hydroxide, and large pores appear in the CFBC bed ash specimens. Sheng [14] showed that the hydration of cement paste with higher $\mathrm{SO}_{3}$ and $f-\mathrm{CaO}$ content produces more $\mathrm{C}-\mathrm{S}-\mathrm{H}$ and AFt in hydration products. This, in turn, decreases the water flow and ionic diffusion rate. The ISA rate for all mixes in this study is higher than $0.4 \mathrm{ml} / \mathrm{m}^{2} \mathrm{~s}$, implying that CFBC ash does not improve the resistance of liquid penetration. Mix A, which contained lower cement content due to the replacement of cement by CFBC bed ash, exhibited lower strength and higher water absorption. Figure 12 plots the ISA rate versus compressive strength for mixes $\mathrm{A}$ and $\mathrm{B}$ at $60 \mathrm{~min}$. The trend in this figure fits perfectly between all the data points, showing that the linear equation of the relationship 


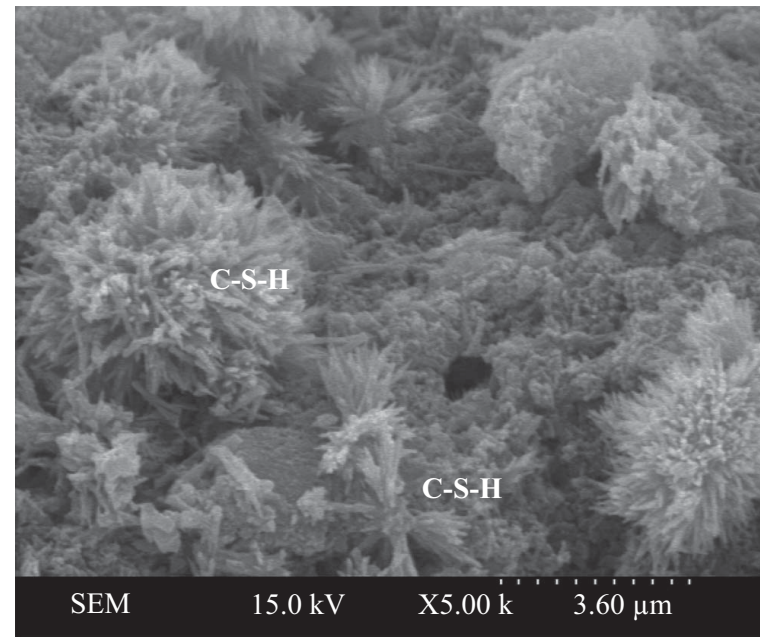

(a)

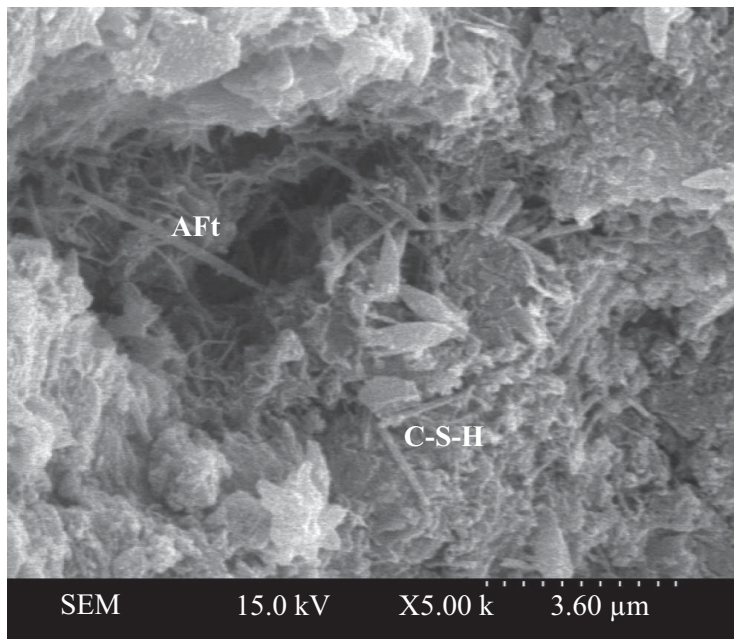

(b)

Fig. 11. SEM micrograph of (a) ordinary Portland cement (b) CFBC bed ash.

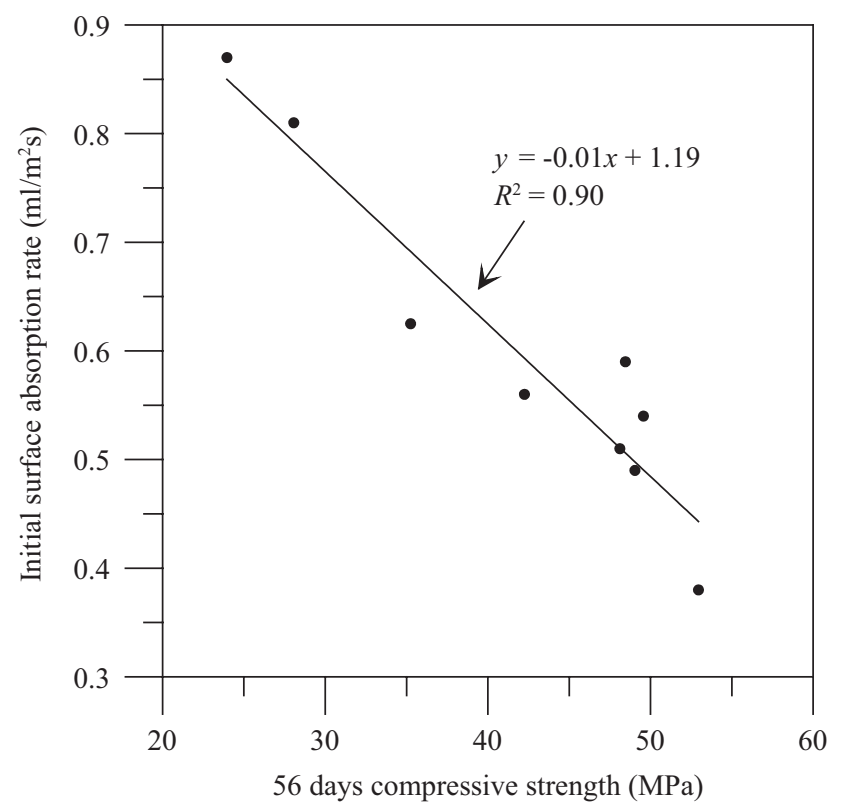

Fig. 12. Relationship between compressive strength and initial surface absorption rate.

between the ISA rate and compressive strength is $y=-0.01 x+$ 1.19 , with the coefficient of 0.90 .

The ASTM C1202 standard test method for electrical indication of concrete's ability to resist chloride ion penetration monitors the amount of electrical current that is passed through a cylindrical concrete specimen when a $60 \mathrm{~V} \mathrm{DC}$ is applied across the specimen for a period of $6 \mathrm{~h}$. This standard uses five levels to classify the charge as corresponding to chloride ion penetrability: High (>4000 Coulombs), Moderate (2000-4000 Coulombs), Low (1000-2000 Coulombs), Very Low (100-1000 Coulombs), and Negligible (<100 Coulombs). Feldman et al. [10] made some valuable comparisons between
Table 3. Initial current for the mortar sample.

\begin{tabular}{cc}
\hline mix no. & Initial current $(\mathrm{mA})$ \\
\hline A00 & 308 \\
A05 & 318 \\
A10 & 338 \\
A15 & 368 \\
A20 & 388 \\
B05 & 324 \\
B10 & 308 \\
B15 & 336 \\
B20 & 356 \\
\hline
\end{tabular}

results of alternating current method and ASTM C1202, and gave good corrosion relations between initial current (IC) and total charge for a period of $6 \mathrm{~h}$. The total charge is the total current flow during the test duration, and IC represents the value obtained $100 \mathrm{~s}$ after the application of voltage at the beginning of the test. Shane et al. [13] suggested a theoretical correlation between IC and total charge obtained for the constant current, and concluded that this measure can be used to assess the chloride ion penetration resistance of concrete below the $4000 \mathrm{C}$ threshold. The charges obtained for all mixtures exceed 4000 coulombs and samples with "high" chloride penetrability boiled during the test. These high results can be attributed to the high amount of paste, which is more conductive than the aggregates. Table 3 lists the initial currents for all mixtures, showing that $\mathrm{CFBC}$ replacement for cement has beneficial effects, as it drastically reduces chloride penetrability. A linear fitting between the initial current and CFBC replacement for cement exhibits a great correlation coefficient of 0.97 , as Fig. 13 indicates. Table 3 also indicates an increase in the initial current as more sand is replaced with CFBC bed ash. This also leads to an increase in compressive strength and a decrease in the initial surface absorption rate, as depicted in 


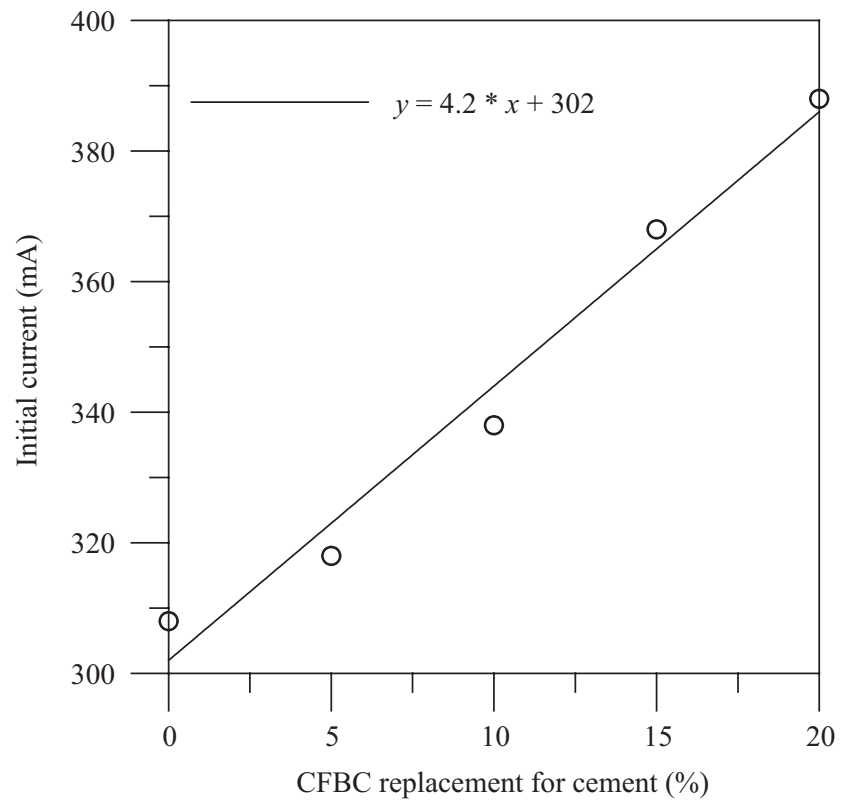

Fig. 13. Relationship between initial current and cement content.

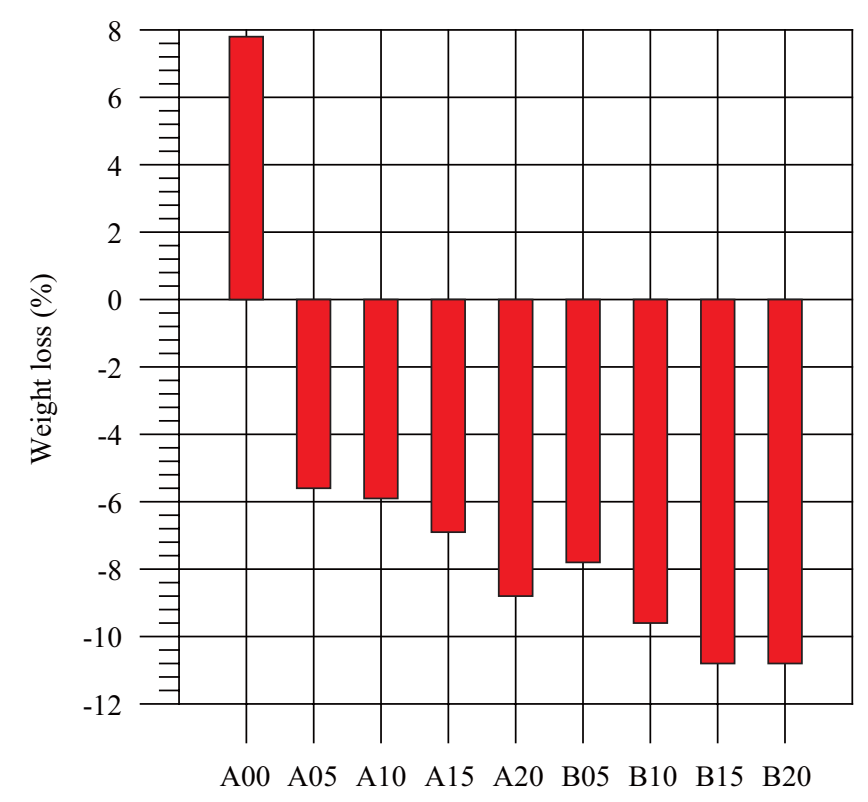

Fig. 14. Weight loss of mortar after seven cyclic exposures.

Fig. 8 and Fig. 10.

\section{CFBC Bed Ash Effect on Sulfate Resistance}

After seven cycles of wet-and-dry exposures, a significant weight increased was recorded for CFBC bed ash mortar samples. This exhibits a strong sulfate attack on CFBC bed ash mortar specimens. Figure 14 show that an increase in CFBC content caused a significant increase in weight. The surface defects of tested specimens also show qualitative evidence of sulfate attack. The positive effect of bed ash on sulfate resistance in concrete is very prominent, as Fig. 15

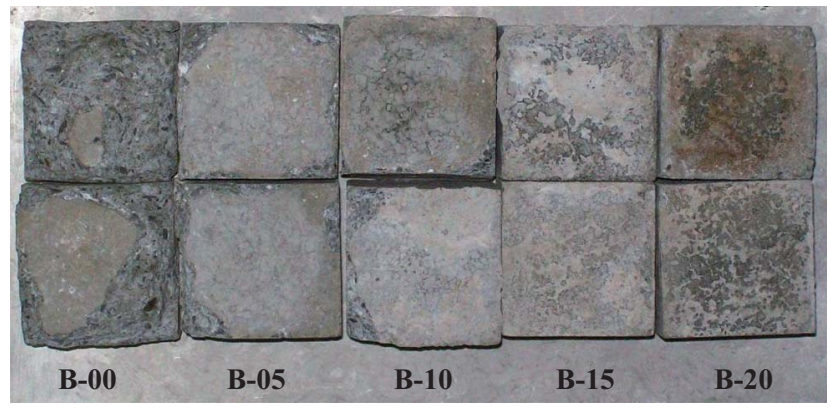

Fig. 15. Surface defects of concretes after seven cyclic exposures for Mix B.

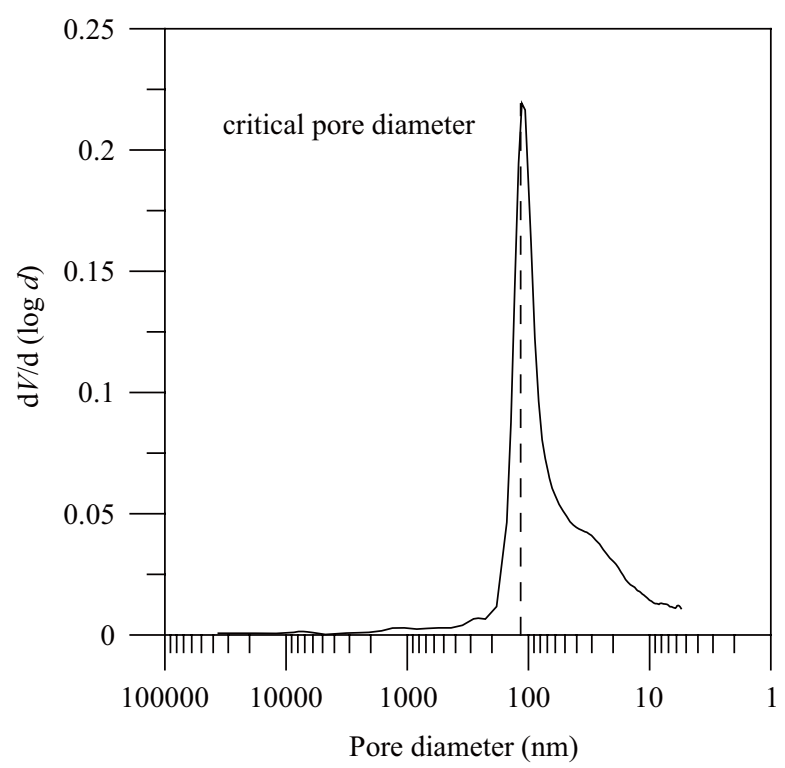

(a)

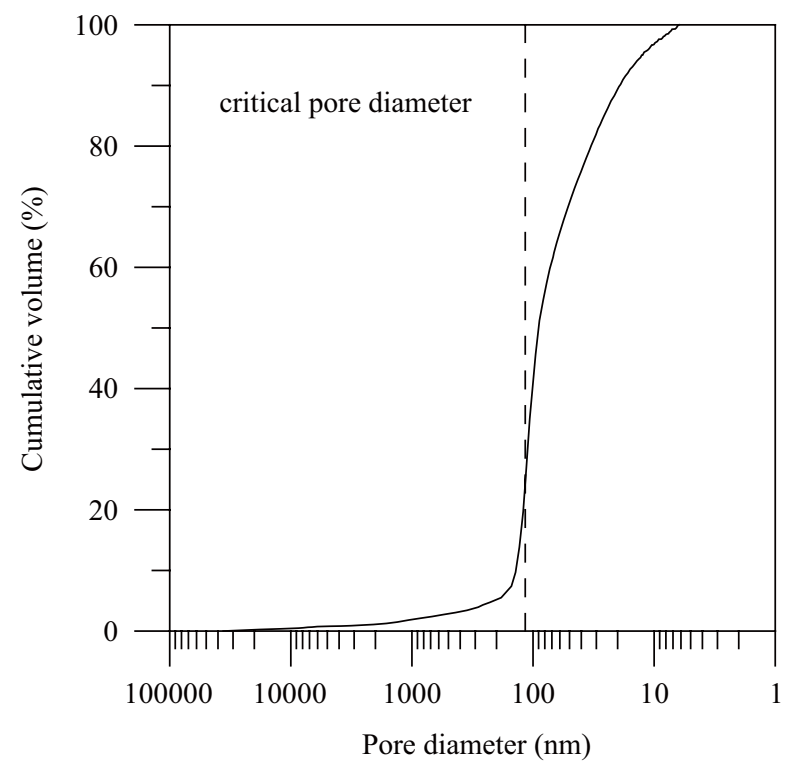

(b)

Fig. 16. Log differential pore volume $\mathrm{d} V / \mathrm{d}(\log d)$ and cumulative pore volume vs. pore diameter. 


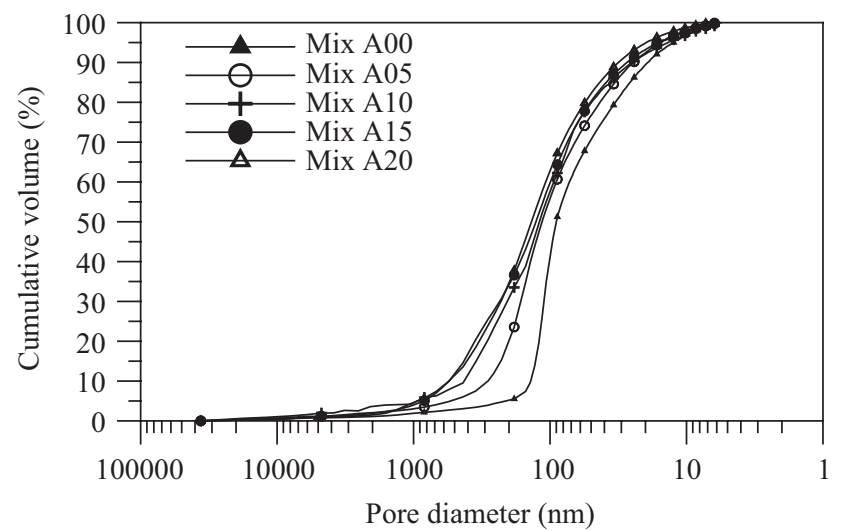

(a)

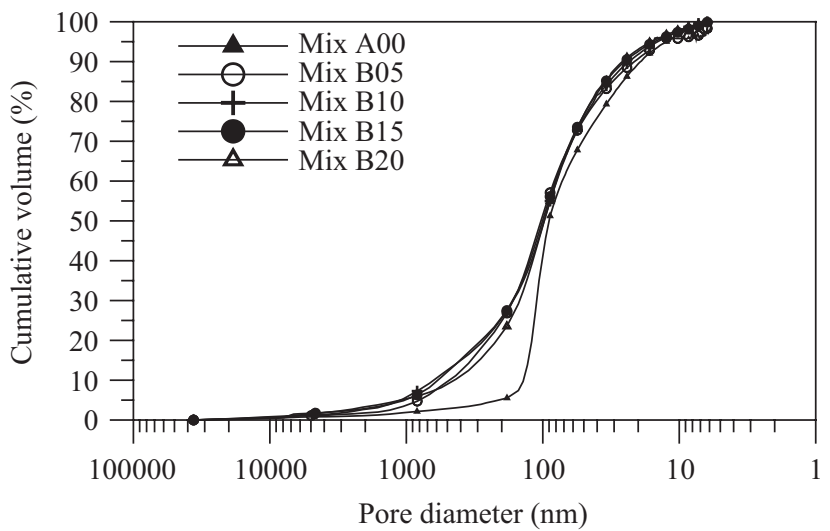

(b)

Fig. 17. Cumulative intrusion and pore size diameter of cement pastes with CFBC bed ash.

Table 4. The capillary porosity and the critical pore diameter of mortar mixtures.

\begin{tabular}{lcccc}
\hline Mix. no. & $\begin{array}{c}\text { Critical pore } \\
\text { diameter }(\mathrm{nm})\end{array}$ & $\begin{array}{c}\text { Total pore } \\
\text { porosity }(\%)\end{array}$ & $\begin{array}{c}\text { Capillary } \\
(>10 \mathrm{~nm}) \text { pore } \\
\text { porosity }(\%)\end{array}$ & $\begin{array}{c}\text { Gel }(<10 \mathrm{~nm}) \\
\text { pore porosity } \\
(\%)\end{array}$ \\
\hline A00 & 115.9 & 20.64 & 20.00 & 0.64 \\
A05 & 166.0 & 20.11 & 19.66 & 0.45 \\
A10 & 349.8 & 23.71 & 23.37 & 0.34 \\
A15 & 401.6 & 24.82 & 24.32 & 0.50 \\
A20 & 471.2 & 24.83 & 24.19 & 0.64 \\
B05 & 255.3 & 23.18 & 22.69 & 0.49 \\
B10 & 266.3 & 23.95 & 23.35 & 0.6 \\
B15 & 372.6 & 23.28 & 23.40 & 0.74 \\
B20 & 408.8 & 22.54 & 21.59 & 0.95 \\
\hline
\end{tabular}

illustrates. The $\mathrm{CFBC}$ bed ash can react with $\mathrm{C}_{3} \mathrm{~A}$ such that reduce the potential of reforming ettringite. The initial reaction of $\mathrm{C}_{3} \mathrm{~A}$ is $\mathrm{C}_{3} \mathrm{~A}+3 \mathrm{C}_{\bar{s}}^{-} \mathrm{H}_{2}+26 \mathrm{H} \rightarrow \mathrm{C}_{6} \mathrm{~A} \bar{s}_{3} \mathrm{H}_{32}$ (ettringite). If all the sulfate is consumed before the $\mathrm{C}_{3} \mathrm{~A}$, then ettringite transforms to another calcium sulfoaluminate hydrate containing less sulfate: $2 \mathrm{C}_{3} \mathrm{~A}+$ ettringite $+4 \mathrm{H} \rightarrow 3 \mathrm{C}_{4} \mathrm{~A} \bar{s} \mathrm{H}_{12}$ (monosulfoaluminate). When monosulfoaluminate comes into contacts with a new source of sulfate ion, then ettringite can be formed once again: monosulfoaluminate $+2 \mathrm{C}^{-} \mathrm{H}_{2}+$ $16 \mathrm{H} \rightarrow$ ettringite. This potential for reforming ettringite is the basis for sulfate attack on cement-based materials exposed to sulfate ions.

\section{Porosity Measurements}

Most of the properties of hardened concrete are related to the quantity and the characteristics of the pores in the concrete. This study shows that strength, durability, permeability, and ionic diffusion are directly influenced or controlled by the amount, size and connectivity of pores. The traditional classification of pores in concrete considers two classes: gel pores $(10 \mathrm{~nm})$, which are associated with the formation of hydration

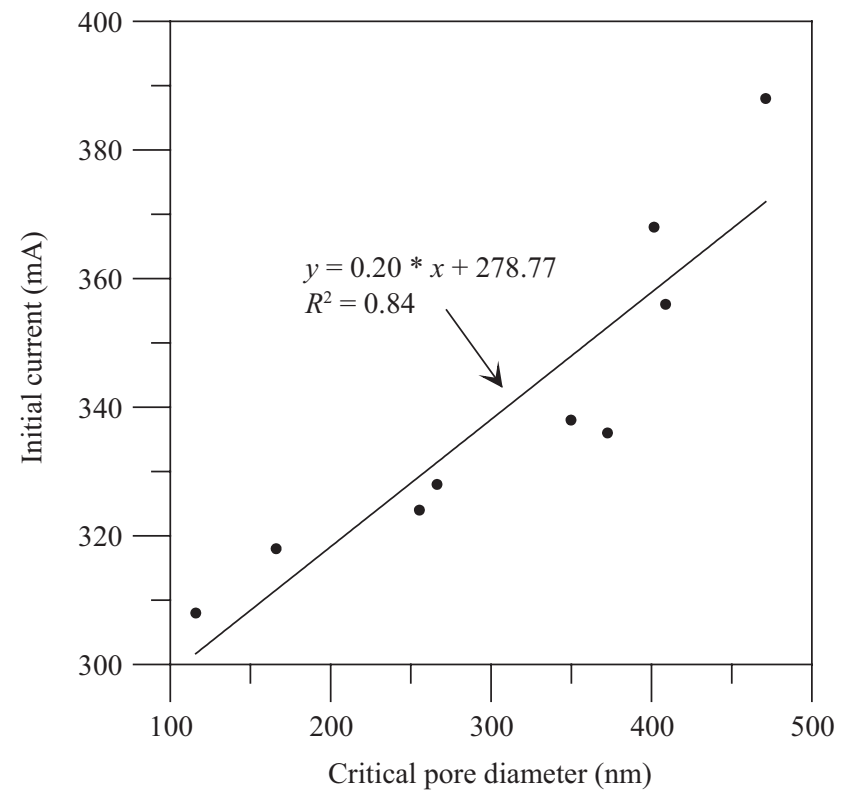

Fig. 18. Relationship between critical pore diameter and initial current.

products, and capillary pores (10 to $10000 \mathrm{~nm}$ ). Figure 16 presents the critical pore diameter for paste samples, and Table 4 lists the capillary/gel porosity and critical pore diameters. Figure 17 presents the MIP curves for paste samples. This figure shows that 20\% CFBC replacement for Portland cement leads to the highest proportion of total pores, while the control mix exhibits the lowest number of pores. The volume of capillary pores increases as CFBC bed ash is added to the mixtures; however, $15 \%$ to $20 \%$ CFBC bed ash replacement for sand produces higher gel porosity. This implies that CFBC bed ash can function as filler for pores in the mortar. The critical pore diameter correlates with the initial current from the chloride ion penetration resistance test, as Fig. 18 shows, indicating that critical pore diameter is positively correlated with the initial current. This suggests that pore structure may be related to chloride penetrability. Thus, 
the effect of CFBC bed ash replacement on chloride penetrability is due to a decrease in the pore size opening.

\section{CONCLUSIONS}

This study illustrates the influence of CFBC bed ash on various mortar properties and behavior, drawing the following conclusions:

1. As more cement is replaced by $\mathrm{CFBC}$, the compressive strength decreases and the ISA rate increases. At $5 \%$ and $20 \%$ CFBC substitutions for Portland cement, the compressive strength fell from 87.7 to $49.8 \%$ after 56 days. Also, replacing more sand with CFBC increased the compressive strength and decreased the ISA rate.

2. Due to a reduction in the fineness of modulus, the flowing ability of mortars decreases as the CFBC bed ash content increases.

3. The CFBC bed ash mortar shrank less than PC mortar initially.

4. According to the results of weight loss, the additions of CFBC bed ash can significantly improve the sulfate resistance of concrete.

5. There is a linear relationship between the ISA rate and compressive strength.

6. The IC measured during the chloride ion penetration resistance test correlates well with the critical pore diameters of mortar.

\section{ACKNOWLEDGMENTS}

The authors are grateful for the support of this research by National Science Council, ROC, under contract No. NSC 96-2218-E-197-003.
1. Anthony, E. J., Jia, L., Caris, M., Preto, F., and Burwell, S., "An examination of the exothermic natural of fluidized bed combustion (FBC) residues," Waste Management Journal, Vol. 19, pp. 293-305 (1999).

2. ASTM Standard C109, "Standard test method for compressive strength of hydraulic cement mortars," Vol. 4.01 (2007).

3. ASTM Standard C150, "Standard speciation for poland cement test," Vol. 4.01 (2007).

4. ASTM Standard C267, "Standard test methods for chemical resistance of mortars, grouts, and monolithic surfacing and polymer concretes," Vol. 4.05 (2001).

5. ASTM Standard C1202, "Standard test method for electrical indication of concrete's ability to resist chloride ion penetration," Vol. 4.02 (2007).

6. ASTM Standard C1437, "Standard test method for flow of hydraulic cement mortar," Vol. 4.01 (2007).

7. Brandstetr, J., Havlica, J., and Odler, U., "Properties and use of solid residue from fluidized bed coal combustion," In: Chandra, S. (Ed.), Waste Materials Used in Concrete Manufacturing, Noyes Publication, New Jersey, pp. 1-47 (1997).

8. British Standard Institution, "Test methods for hardened concrete other than compressive strength: BS1881, part 201- initial surface absorption of water test" (1983).

9. Conn, R. E. and Sellakumar, K., "Utilization of CFB fly ash for construction applications," Proceedings of the $15^{\text {th }}$ International Conference on Fluidized Bed Combustion, Savannah, Georgia, pp. 507-518 (1997).

10. Feldman, R. F., Chan, G. W., Brousseau, R. J., and Tumidajski, P. J., "Investigation of the rapid chloride permeability tests," ACI Material Journal, Vol. 91, pp. 246-255 (1994).

11. Freidin, C., "Influence of variability of oil shale fly ash on compressive strength of cementless building compounds," Construction and Building Materials, Vol. 19, pp. 127-133 (2005).

12. Kumar, R. and Bhattacharjee, B., "Assessment of permeation quality of concrete through mercury instruction porosimetry," Cement and Concrete Research, Vol. 34, pp. 321-328 (2004).

13. Mindess, S., Young, J. F., and Darwin, D., Concrete, $2^{\text {nd }}$ Ed., Prentice Hall, USA (2002).

14. Sheng, G., Li, Q., Zhai, J., and Li, F., "Self-cementitious properties of fly ashes from CFBC boiler co-firing coal and high-sulphur petroleum coke," Cement Concrete Researsh, Vol. 37, pp. 871-876 (2007).

15. Zhang, H. and Qiu, K., "The proposed utilization of fluidized bed combustion ash in the production of a special cement," Proceedings of $14^{\text {th }}$ International Conference on FBC, ASME, Vancouver, Vol. 2, pp. 699702 (1999).

\section{REFERENCES}

